\title{
Precuela de la novela de Sergio Ramírez, Ya nadie llora por mí Doña Sofía
}

Gabriela Segura Umaña

D oña Sofía, era una mujer como cualquier otra de los barrios pobres de Managua. Una mujer muy trabajadora, que todos los días se levantaba a las 4 a.m. para empezar el día con tortillas palmeadas, a las cuales les arrimaba un puñito de frijoles, un pedazo de cuajada y su buena taza de café. Todo esto acompañada del típico aroma que se desprendía de aquellos trozos de madera que poco a poco se desvanecían dentro de la cocina.

Al salir de su casa, en dirección al trabajo, saludaba a esas otras mujeres del barrio, que desde muy temprano ya se encontraban montando sus puestos de comida en la esquina, y a aquellas otras que lavaban afanosamente las aceras. También saludaba al señor que no tenía hogar y que vagaba entre las tres calles cercanas a su casa. De vez en cuando le llevaba su "aliñito" de tortillas, que intercambiaba por las últimas noticias que acontecían en el barrio cuando ella se encontraba trabajando.

En fin, doña Sofía era una mujer muy querida y respetada en el barrio, se preocupaba por la gente. Era, como ella misma decía, una mujer de fe que obra por el bien. No era exactamente una fervorosa devota, sino una mujer que había sido criada como católica, y guiaba sus acciones según su instinto de buena cristiana. Sí, había sido criada como católica, aunque eso con el tiempo y con las circunstancias hubo de cambiar.

Doña Sofía era una mujer joven, sin embargo había aceptado el título de doña con orgullo, puesto que la ligaba directamente a su hijo: José Ernesto, a quien amaba de manera incondicional. Él, ya tenía dos años de que se había ido a vivir de manera regular a la ciudad de León, departamento ubicado al noreste de la ciudad de Managua, a unos 90 kilómetros aproximadamente, allí era donde estudiaba, y solo volvía a Managua para pasar las vacaciones.

Era el año 1978, se encontraba en el poder Anastasio Somoza Debayle, dictador de Nicaragua, tercer y último miembro de la dinastía somocista, luego de su padre, Anastasio Somoza García, y su hermano, Luis Somoza Debayle, quienes habían ejercido el poder dictatorial en Nicaragua desde 1937. Sin embargo, ya para esos 
años la situación en Nicaragua era convulsa y a la capital llegaban rumores sobre grupos guerrilleros en las montañas. Doña Sofía, ajena a la política, seguía de cerca las noticias y rumores, pero no se detenía demasiado en esos temas. Existían otras necesidades sentidas a flor de piel que la ocupaban diariamente.

Era abril, y transcurrió un día normal en la vida de doña Sofía. A eso de las 4 p.m. salió de su trabajo rumbo a su casa. Era una tarde calurosa, los últimos rayos de sol hacían sentir que quemaba la piel. Doña Sofía caminaba entre las ventas de comida, ropa y cualquier producto, que se encontraban cerca de la parada de bus que la llevaría hasta su casa. Una vez en el barrio ya todo era más fresco, se sentía una brisa que calmaba todo alrededor. Era su momento favorito del día.

De lejos vio su casita, y fue grande la sorpresa cuando al entrar vio en la sala a José Ernesto. Primero sintió muchísima alegría, hacía más de dos meses que no estaban cerca; sin embargo, también la invadió un terror que no podía explicar, no era normal que él estuviera ahí.

Por primera vez lo vio distinto, como envejecido de pronto. Él estaba muy feliz de verla, pero sabía que lo que le venía a decir cambiaría para siempre la relación entre ellos. Cuando ya se pudieron sentar a conversar, se confirmaron todos los temores de doña Sofía, José Ernesto estaba ahí porque se había unido a la guerrilla, y a pesar de los códigos de seguridad había decidido ir hasta Managua a hablar con su madre, porque pronto se iría a cumplir tareas asignadas en algún lugar de Nicaragua.
Fue una noche terrible, doña Sofía no podía comprender por qué José Ernesto tomaba esa decisión, y no hubo forma de que él le pudiera explicar el porqué de la lucha, para doña Sofía nada de eso tenía sentido. Se preguntaba a sí misma en qué había fallado, qué era lo que su hijo necesitaba y ella no se lo había podido dar. Le suplicó que desistiera de esa idea, que volviera a la universidad o que se fueran juntos a otro país. Nada podía cambiar ya la decisión de José Ernesto. Él le dijo que lo hacía porque era lo correcto, que lo hacía incluso por amor a ella, pero para doña Sofía eran palabras vacías. Al día siguiente cuando despertó, deseó que todo hubiera sido una pesadilla, pero no era así, José Ernesto ya se había ido.

Con una gran pesadez se levantó y cumplió con su habitual rutina para salir temprano a trabajar, se sentía como levitando por su casa, por su barrio, por las calles de Managua, y de pronto su ensoñación quedó interrumpida cuando escuchó por medio de un noticiario que la Guardia Nacional había capturado y ejecutado a un pequeño grupo guerrillero cerca del departamento de Jinotega. Esa era una noticia que otras veces ya había escuchado pero que ahora la impactaba directamente, y sintió terror al pensar en su hijo. Ahora no sabía dónde estaría él, y si acaso se encontraba en peligro.

Pasaron los días y doña Sofía no podía pensar en otra cosa, cada día estaba más al pendiente de las noticias que se rumoraban, pero se dio cuenta de que era muy poco lo que se decía acerca de estos grupos, se decía que eran pocos, que no estaban organizados y que Somoza junto 
con la Guardia Nacional tenían todo bajo control, por la seguridad del país. Ahora la casa de doña Sofía estaba llena de periódicos, que compraba con desesperación para encontrar algún indicio, pero de nada le servía porque realmente no sabía qué estaba buscando.

Una tarde en la que doña Sofía se sentía desesperanzada, recordó de pronto que había escuchado alguna vez acerca de que un grupo de vecinos de su barrio se reunía de vez en cuando para hablar sobre estos grupos guerrilleros; así que sin dudarlo se fue a buscar a una de sus vecinas, cuando llegó, bastante alterada, le hizo todo tipo de preguntas sin ningún orden y algunas sin ningún sentido. Fue como abrir un grifo del cual salían a chorros todos los temores y prejuicios de doña Sofía.

Una vez que la vecina logró tranquilizarla y comprender por qué ella hacía todas esas preguntas, le dijo que no era seguro en ese momento hablar sobre todo lo que ella le estaba preguntando, pero que la invitaba a la siguiente reunión que harían entre los vecinos y allí ella podría, entonces, enterarse un poco más sobre lo que estaba aconteciendo en el país.

Y así fue, el día de la esperada reunión llegó y doña Sofía desde buena mañana se encontraba muy ansiosa por asistir, tan ansiosa que pasó toda la tarde palmeando tortillas, ya que no sabía qué otra cosa hacer con sus manos, y ya no podía soportar más sentirse inmóvil. Cuando se dirigió al punto de encuentro, llevó en una bolsa de tela todas las tortillas que había preparado, esperando que a alguien se le ocurriera llevar café y cuajada, además de que llevaba de manera visible una biblia que le habían pedido que llevara consigo.

Cuando entró en la casa a donde la habían convocado, vio con sorpresa que los vecinos que se encontraban ahí eran aquellos que ella reconocía por reunirse constantemente para hacer estudios de la biblia y a los que ella siempre les rechazaba la invitación, y pensó que seguramente le habían jugado una mala pasada y aprovechándose de su desesperación la habían convocado, engañada, para traerla de nuevo a los caminos de Dios, más ahora que sabían que ella estaba interesada en saber sobre los grupos guerrilleros.

Sin embargo, más grande fue su sorpresa al darse cuenta de que aquello de los estudios de la Biblia no era más que una pantomima. Entró a la casa y se sentó en una esquina, donde escuchó atentamente todos los puntos de la agenda sobre los cuales hablarían en esa noche. Como último punto de agenda dijeron "Doña Sofía" y ella sintió que se le iba a salir el corazón.

Escuchó durante toda la reunión todos los principios e ideales por los cuales estaban luchando, palabras como opresión, lucha de clases, emancipación...la llenaron de más dudas que las que llevaba. Todos hablaban como si no importara que ella estuviera ahí, talvez porque sabían muy bien que tarde o temprano doña Sofía se uniría a la causa. Al llegar al último punto, le preguntaron que si ella deseaba decir algo, que si tenía dudas, y ella apresuradamente dijo que no quería tener que ver con ellos y con su lucha, pero que necesitaba saber qué estaba pasando porque su hijo se había ido. 
De esta manera, todos la escucharon atentamente, y cuando al fin dijo todo lo había estado conteniendo en su pecho durante días, procedieron a explicarle la complejidad de las estructuras y que ellos realmente no podrían darle explicación de dónde estaría su hijo, pero nuevamente la invitaron a formar parte del grupo que era de colaboración con las redes clandestinas. Le dijeron que talvez esa podría ser una opción para ella, para que su hijo estuviera bien y muchas otras personas en general.

Doña Sofía guardó silencio por un largo rato, y finalmente dijo que sí. Para ella se convirtió en una lucha personal por el bienestar de su hijo, aunque no tenía muy claro cómo eso sería así, pero sí sabía que no podía soportar más la inmovilidad con la que había estado lidiando los últimos días.

Fue así como poco a poco se le asignaron pequeñas tareas a doña Sofía, las cuales fue cumpliendo con su mayor devoción, primero se encargó de llevar las minutas de las reuniones y posteriormente esconderlas; y luego se le dio una tarea sencilla pero importante: fungir como correo. La primera vez que le tocó esta tarea fue con mucho miedo a dejar un paquete en la banca de un parque, el cual dejó con la mayor discreción para luego salir corriendo a meterse a una tienda para poderse esconder y ver que efectivamente llegara alguna persona a recogerlo. Luego le explicaron que eso estaba prohibido.

Así fueron pasando los meses siguientes y doña Sofía cada vez contaba con mayor propiedad al cumplir sus tareas y al asistir a las reuniones, ahora planteaba más abiertamente sus criterios y estrategias de acción, a veces un poco descabellados pero sorprendentemente efectivos. Así iba, pensando que lo hacía por su hijo, que tarde o temprano todo acabaría, aún no sabía cómo, pero que todo estaría bien y volvería a la normalidad, como antes. Pensó entonces que cuando eso pasara decidiría irse a vivir a León.

Para inicios del mes de marzo de 1979, era de noche cuando llamaron a su casa, era uno de los vecinos del grupo, llegó con dos muchachos y con la solicitud de tenerlos esa noche en su casa. Estaban clandestinos. Doña Sofía sabía que esa tarea la posicionaba ya en un lugar muy importante dentro del grupo, así que aceptó con una emoción extraña y sabiendo además que era una tarea que también podía ser muy peligrosa. Esa noche no durmió, se quedó hablando con los dos muchachos, dos jóvenes que tenían la edad que José Ernesto tenía cuando se fue, hace ya casi un año. Ellos iban de clandestinos hacia Costa Rica, habían participado en varias acciones donde habían logrado detectar quiénes eran, así que sus vidas estaban en riesgo, por lo cual los mandaron a salir del país.

Toda la noche conversaron sobre los ideales del FSLN y de las distintas corrientes dentro de este, además fantasearon con las posibles soluciones al conflicto que ya se veía venir, pero tras horas y horas de hablar se encontraron con un sentimiento de tristeza, pues a pesar de su alegría y de sus convicciones sabían muy bien que en esta la lucha, el desenlace no sería sencillo y que implicaría la muerte de muchos hermanos y hermanas nicaragüenses. Hasta ese momento fue que doña Sofía comprendió que la lucha armada no se elige, 
se impone. Y que fue la única solución que había encontrado su hijo cuando vio que ya no existían otras alternativas. Ahora la decisión de doña Sofía tomaba otro carácter, ya no era ella y su único interés: su hijo, sino que ahora comprendía que había muchos, que era una decisión social.

Unas semanas después recibió una carta, era de José Ernesto, lo sabía porque reconocía su letra. La carta solo decía "Estoy con vida y pronto nos reuniremos". En ese mismo momento, en los días de marzo de 1979 se firmó el acuerdo de unidad por parte de los representantes de las tres fracciones sandinistas y se decide impulsar la lucha. En junio se hizo el llamamiento a la "Ofensiva Final" y a la huelga general y el 19 de julio de 1979 las columnas guerrilleras del FSLN entraron en Managua, con un amplio respaldo popular, consumando la derrota de Anastasio Somoza Debayle.

Todo pasó tan rápido, que ni siquiera doña Sofía podía comprenderlo, el día del triunfo salió a las calles de Managua, celebró con sus vecinos y con un centenar de personas que nunca había visto y jamás volvió a ver otra vez. En su corazón no cabía la alegría, estaba convencida de que ahora todo sería diferente, ya no quería que fuera como antes.

Días después del triunfo, sus compañeros de barrio tocaron a su casa, y lo supo desde el primer momento en que los vio, su hijo José Ernesto, quien había sido William en la guerra, había caído en el operativo del hospital bautista en el Oriental, unos días antes del triunfo. 
